\title{
A RELAÇÃO ENTRE PROVA PROCESSUAL E VERDADE DOS FATOS JURÍDICOS DIANTE DO PENSAMENTO DE PONTES DE MIRANDA
}

\author{
ADRUALDO DE LIMA CATÃO*
}

\begin{abstract}
RESUMO: Esse trabalho pretende apresentar a visão de Pontes de Miranda sobre a relação entre verdade e processo. A ideia é demonstrar que a teoria do fato jurídico e a noção de incidência da norma podem servir de base para uma postura não relativista sobre a verdade no processo judicial. Nesse sentido, pretende-se apresentar o processo como ambiente complexo, porém, cognitivo, demonstrando-se a viabilidade da noção de verdade no processo e criticando-se a distinção entre verdade real e verdade processual. Termina por defender uma espécie de falibilismo.

PALAVRAS-CHAVES: Prova; Verdade; Processo Judicial.
\end{abstract}

\begin{abstract}
This work intends to present the vision of Pontes de Miranda on the relationship between truth and the judicial procedure. The idea is to demonstrate that the theory of legal fact and the notion of normative incidence can be the basis for a non relativist posture about the truth in judicial proceedings. Accordingly, we intend to present the judicial procedure as complex environment, however cognitive, demonstrating the feasibility of the concept of truth in the judicial procedure and criticizing the distinction between procedure truth and real truth. Ends up defending a kind of fallibilism. KEYWORDS: Evidence; Fact; Judicial Procedure.
\end{abstract}

SUMÁRIO: 1. A complexidade da interpretação em Pontes de Miranda; 2. A relação entre a prova judicial e a verdade; 3 . As limitações processuais à verificação dos fatos; 4. A prova judicial e o dever de verdade; Referências bibliográficas.

SUMMARY: 1. The complexity of interpretation in Pontes de Miranda, 2. The relation between judicial proof and the truth 3 . The procedural limitations to the verification of facts, 4 . The judicial proof and the duty of truth; References.

\section{A COMPLEXIDADE DA INTERPRETAÇÃO EM PONTES DE MIRANDA}

Uma crítica recorrente ao pensamento pontesiano quanto aos fatos jurídicos e à noção de incidência infalível é a de que ela seria uma simplificação do raciocínio jurídico e que, portanto, deixaria de lado a complexidade da interpretação do Direito.

Artigo recebido em 28.08.2010. Pareceres emitidos em 29.11.2010 e 30.12.2010.

Artigo aceito para publicação em 6.01.2011.

* Mestre e Doutor em Teoria e Filosofia do Direito pela Faculdade de Direito do Recife/UFPE. Professor da Graduação e do Mestrado da Faculdade de Direito de Alagoas/UFAL. 
Nesse artigo se pretende demonstrar um importante aspecto da Teoria do Fato Jurídico, que é impropriedade dessa crítica.

A Teoria do Fato Jurídico é compatível com a visualização da complexidade da interpretação jurídica e com a verificação dos fatos por meio das provas, justamente porque ela não se confunde com a Teoria das Provas, tanto quanto a incidência não se confunde com a aplicação do Direito.

Nesse trabalho, reforça-se, assim, a distinção entre incidência e aplicação, mostrando-se que a complexidade pragmática está justamente no segundo momento, que é a aplicação do Direito. Esse momento não é parte da formalização lógica pretendida com a Teoria do Fato Jurídico, e é nele que se discutem as diversas questões pertinentes à Teoria das Provas.

Pois bem, para demonstrar que Pontes de Miranda aceita a complexidade da aplicação do Direito, destaca-se um aspecto tipicamente pragmático que podemos visualizar no seu pensamento, que se refere a uma visão não essencialista da interpretação jurídica. Sua teoria não vê a norma jurídica como idêntica à lei e destaca a complexidade do seu conhecimento na aplicação do Direito.

A interpretação e aplicação da norma jurídica, portanto, não deve ser considerada um momento cognitivo instantâneo e simples, mas um processo de conhecimento complexo. Desta forma, a infalibilidade da incidência normativa não torna simples a interpretação e a aplicação do Direito.

A ideia da infalibilidade da incidência pode, destarte, conviver com a consideração da complexidade das questões interpretativas, exatamente porque a incidência normativa é meramente lógico-formal:

Como afirma Adriano Soares da Costa:

Como se pode perceber, não era Pontes de Miranda um ingênuo ao formular o conceito operacional de incidência, como se imaginasse ele que as normas jurídicas não precisassem ser interpretadas, produzidas em certo sentido, passando por todo um processo complexo até se tornarem um dado para a sociedade, uma norma viva. ${ }^{1}$

Pontes de Miranda separa a lei da norma jurídica. Nesse sentido, a lei é somente a exteriorização da norma jurídica, mas não a sua substância. A lei confere sistematicidade à empiricidade dos fatos que a norma jurídica regula. Se uma sentença que decidiu com base em erro transita em julgado, trata-se de prevalência do interesse na segurança jurídica em detrimento da efetiva realização do Direito objetivo. ${ }^{2}$

É a lei, portanto, simples fase intermédia e distinta, fixa e descontínua, entre duas efetivas representações do Direito em si: o que as circunstâncias

${ }^{1} \mathrm{O}$ autor considera a incidência sob um aspecto diferente do que aqui se quer apresentar. Ele trata a expressão "mundo do pensamento" como o mundo 3 de Popper, na esteira de Frege. COSTA, Adriano Soares. Teoria da incidência da norma jurídica: crítica ao realismo lingüístico de Paulo de Barros Carvalho. São Paulo: Malheiros, 2009, p. 45.

${ }^{2}$ CASTRO, Torquato. Teoria da situação jurídica em direito privado. Anuário do Mestrado em Direito do Recife. N. 1. Jan./Dez. 1976, p. 31 e 33. 
pedem para corrigir os defeitos da adaptação do homem à vida social e o que de fato se aplica ou vai aplicar-se aos casos concretos de inadaptação. ${ }^{3}$

Como vimos, Pontes de Miranda deixa de lado a ideia de coercibilidade para enfatizar o aspecto sociológico do Direito. Destarte, deduz que legislar é sempre perigoso, pois quando não for observada a Lógica e a vontade social, presentes nos fatos, produzir-se-á leis falsas, sem função social, já que deslocadas da complexidade dos fatos sociais. ${ }^{4}$

Na sua postura sociológica, mais um aspecto pragmático pode ser apontado em sua visão da interpretação. Ao negar que o Direito signifique aderir a princípios gerais, defende uma visão indutiva na construção da lei baseada nos fatos, deixando de lado o conceitualismo e abrindo caminho para a importância dos fatos sociais na interpretação do Direito.

A falta de importância capital do texto legal aparece na teoria pontesiana como elemento da sua teoria sociológica do Direito, que, como visto, trata o Direito como fato e não como ato de vontade. A interpretação da lei, portanto, deve recorrer aos fatos tanto quanto o legislador precisa fazê-lo. Assim, para Pontes de Miranda, "não existe diferença material entre interpretação e legislação". 5

Vê-se, portanto, que a lei está entre dois fatos sociais, quais sejam, as relações sociais que geram a lei, e a aplicação da lei no momento concreto. O momento da aplicação e da interpretação da lei só faz sentido por causa da falta de adaptação social, que provoca conflitos quando o Direito não ocorre espontaneamente.

A operação para interpretar a lei é sempre indutiva e complexa, e deve descer aos fatos para encontrar o que seria a substância da norma jurídica. Pontes de Miranda afirma que o problema das leis aparece justamente quando elas não resultam de induções sociológicas. Os princípios gerais contidos nas constituições e nas leis não dependem da verdade do que afirmam, pois elas se impõem pela autoridade e não pelos fatos. ${ }^{6}$

Desta forma, a lei pode não conter o conteúdo da norma jurídica, cabendo ao intérprete mais do que simplesmente aplicar o sentido literal da norma jurídica:

O aplicar a lei porque está na lei, o resolver pelo sentido literal, porque assim quis o legislador, corresponde ao fazer porque está no Evangelho, no Talmude, no Korão, no Corpus Iuris, porque o nosso pai fez, e ao ingênuo "porque mamãe disse" das criancinhas.

\footnotetext{
${ }^{3}$ PONTES DE MIRANDA, Francisco Cavalcante. Sistema de Ciência Positiva do Direito. Campinas: Bookseller, Tomo 3, 2005, p. 29.

${ }^{4}$ GUSMÃO, Paulo Dourado de. As idéias do jovem Pontes de Miranda. Conferências do III Congresso Brasileiro de Filosofia do Direito: em homenagem a Pontes de Miranda. João Pessoa: Edições Grafset, Jun. 1988, p. 125.

${ }^{5}$ PONTES DE MIRANDA, Francisco Cavalcante. Sistema de Ciência Positiva do Direito. Campinas: Bookseller, Tomo 2, 2005, p. 217.

${ }^{6}$ PONTES DE MIRANDA, Francisco Cavalcante. Sistema de Ciência Positiva do Direito. Campinas: Bookseller, Tomo 4, 2005, p. 144.

${ }^{7}$ PONTES DE MIRANDA, Francisco Cavalcante. Sistema de Ciência Positiva do Direito. Campinas: Bookseller, Tomo 2, 2005, p. 102.
} 
Pontes de Miranda, evidentemente, não nega o valor da lei, somente destaca sua historicidade. O princípio da lei como fonte única de Direito, nesse sentido, é só uma conquista histórica da modernidade, mas não deve ser considerada uma característica essencial, encontrada em qualquer sistema jurídico.

A correspondência das leis aos fatos se dá de duas formas. Antes da elaboração da lei, é papel do legislador fazer as induções sociológicas, e após, é função do intérprete ou aplicador do Direito fazer as mesmas induções na construção do sentido do texto legal. A correspondência com os fatos, entretanto, não deve ser considerada imediata, pois a adequação pragmática por parte do intérprete jurídico se faz sempre necessária.

Deve a Ciência do Direito recorrer ao método indutivo "nas três fases da elaboração jurídica, - na pré-legislativa ou doutrinária, na legislativa e na pós-legislação ou exegética(...)" ${ }^{8}$ De tal modo, ao legislador cabe visualizar a realidade tanto quanto o jurista, sendo que, quando o legislador falha, cabe ao intérprete fazer a interpretação mais adequada, sempre baseada nos fatos sociais.

A Ciência do Direito tem que ser ciência de fatos e não de textos. Isto fica claro quando Pontes de Miranda define o Direito como processo de adaptação e não como conjunto de normas. Por isso a importância do Direito legislado é apenas parcial. “Os atos jurídicos, os atos da vida, que não vão aos tribunais, são o maior repositório do Direito aplicado" 9 .

Nesse sentido, também a determinação do sentido da regra jurídica não pode ser considerada atributo independente da interpretação e dos fatos sociais:

Para que se saiba qual a regra que incidiu, que incide, ou que incidirá, é preciso que se saiba o que é que se diz nela. Tal determinação do conteúdo da regra jurídica é função do intérprete, isto é, do juiz ou de alguém, jurista ou não, a quem interesse a regra jurídica. ${ }^{10}$

Deve-se destacar que a interpretação do Direito, feita pelo intérprete autêntico ou não, é sempre complexa e envolve elementos subjetivos, não havendo que se falar em objetividade do texto legal, resultando em mais uma concessão pragmática no pensamento pontesiano.

Ao intérprete é possível, inclusive, estender o conteúdo da regra aos fatos por ela não previstos, bem como atuar onde há lacunas e buscar, contra legem, a regra jurídica correta quando ela não está contida na lei, deixando-se de completamente de lado uma visão essencialista da interpretação. ${ }^{11}$

${ }^{8}$ PONTES DE MIRANDA, Francisco Cavalcante. Sistema de Ciência Positiva do Direito. Campinas: Bookseller, Tomo 4, 2005, p. 53.

${ }^{9}$ PONTES DE MIRANDA, Francisco Cavalcante. Sistema de Ciência Positiva do Direito. Campinas: Bookseller, Tomo 4, 2005, p. 139.

${ }^{10}$ PONTES DE MIRANDA, Francisco Cavalcante. Tratado de Direito Privado. Campinas: Bookseller, Tomo 1, 1999, p. 13-14.

${ }^{11}$ PONTES DE MIRANDA, Francisco Cavalcante. Tratado de Direito Privado. Campinas: Bookseller, Tomo 1, 1999, p. 14. 
Ainda sobre a clareza, Pontes de Miranda afirma:

O ideal de cada momento seria o Direito em que tudo estivesse claro e preciso; mas ofenderia a outro ideal, dentro do tempo, que é o da função adaptativa do Direito. Por isso, o juiz deve afastar-se do texto legal quando, deixando de aplicá-lo, serve ao Direito do seu momento, porque, com tal procedimento, atende aos dois ideais aparentemente inconciliáveis: o da fixidez e o de mutação. ${ }^{12}$

O processo de aplicação da lei, portanto, tem função adaptativa (de correção dos defeitos de adaptação) e depende da interpretação jurídica. Fica claro que a diferença entre incidência e aplicação não deve implicar, destarte, a defesa de uma objetividade da interpretação no pensamento de Pontes de Miranda.

Deve-se destacar, inclusive, que a relação entre o conteúdo da lei e o fato concreto é quase sempre conflituosa em todos os aspectos da aplicação. Assim, o fenômeno da jurisdicização aparece como um fato determinável e absolutamente independente da atuação do interprete, mas seu conhecimento é sempre uma operação complexa, decorrente da interpretação jurídica.

Destaque-se, todavia, que Pontes de Miranda apresenta a aplicação do Direito como uma operação cognitiva de fatos. Além disso, não se pode deixar de reconhecer que a análise das relações devem ser regradas pela lei, notadamente no Direito moderno. Contudo, para Pontes de Miranda, a aplicação do Direito não se dá como uma operação de subsunção do fato à lei. A regra jurídica não se identifica com a lei, apesar de ter nela uma de suas fontes, já que se devem analisar as normas jurídicas como resultado das relações sociais.

Assim, uma ciência positiva do Direito em Pontes de Miranda não defende uma crença legalista. A lei é um entre tantos outros fatos que forjam o Direito de uma sociedade. O Poder Legislativo e a noção de lei são próprios de uma sociedade moderna, mas não são a essência do Direito.

Ademais, a atenção à exatidão dos conceitos e a referência à Lógica não elidem a necessidade de pesquisa histórica para o conhecimento das regras jurídicas vigentes. O Direito, como fato, aparece numa relação circular com relação à definição da regra jurídica pelo legislador e pelo jurista. Quanto mais próximo da realidade positiva está a proposição legislativa, menos pode o jurista fugir à letra da lei.

Quando fala da linguagem, Pontes de Miranda leva ainda em consideração a pluralidade de emprego da palavra, quando afirma que em algumas situações "a mesma expressão tem de ser interpretada de duas ou três maneiras, devido ao assunto de que se trata.” Isto demonstra que a linguagem que capta a incidência não consegue necessariamente captá-la como um todo, justificando a separação entre incidência e aplicação do Direito. ${ }^{13}$

${ }^{12}$ PONTES DE MIRANDA, Francisco Cavalcante. Sistema de Ciência Positiva do Direito. Campinas: Bookseller, Tomo 2, 2005, p. 266.

${ }^{13}$ PONTES DE MIRANDA, Francisco Cavalcante. Sistema de Ciência Positiva do Direito. Campinas: Bookseller, Tomo 2, 2005, p. 114. 
A norma jurídica incide, mas é sempre preciso definir onde está a norma jurídica. Isso nem sempre está claro, mas o que se pode deduzir da análise do pensamento pontesiano é que a aplicação do Direito encontra a norma jurídica no ambiente complexo dos fatos e não numa exegese literal da lei ou dos costumes. De tal modo, a aplicação exige a consideração da complexidade do mundo dos fatos.

A importância do processo de aplicação aparece exatamente porque ao Direito, como processo social de adaptação, não basta que as regras jurídicas incidam, elas devem ser atendidas pelos utilizadores da linguagem jurídica, e seu atendimento deve ser precedido do conhecimento de tais regras. ${ }^{14}$

Numa clara referência pragmática sobre a diferença entre a regra jurídica e o costume, Pontes de Miranda afirma: "O que se aplicou, o que se respeitou, foi o que se teve como regra jurídica incidente”. ${ }^{15}$ Isso quer dizer que o conteúdo da incidência de uma regra costumeira, pragmaticamente falando, aparece no momento da aplicação. Atribui, pois, ao resultado da aplicação ou da obediência à determinação do conteúdo da regra costumeira incidente.

Pontes de Miranda, obviamente, não vai tão longe a ponto de cair num relativismo de conteúdo no Direito. Subordina a sua livre pesquisa sempre ao método científico, calcado na realidade dos fatos, na história e na quantificação matemática e formalização lógica, como forma de evitar o government by judges.

Ademais, fica claro que a atividade do juiz ou do intérprete, apesar de complexa, é sempre cognoscitiva para Pontes de Miranda. Assim, seria sempre possível errar na definição da regra jurídica, bem como quanto aos fatos. O erro quanto aos fatos, todavia, nem sempre é do juiz, podendo ser também das partes que falharam na produção de provas.

Mesmo quando se esclarece que a definição do conteúdo da regra é papel do intérprete, Pontes de Miranda deixa a esse uma tarefa cognitiva, sem nenhum espaço para a ideia de invenção. "A construção indutiva, que procura a relação entre o fato jurídico e a norma, é mais diagnose do que processo discursivo; auxilia a lógica, a análise, - não para descobrir novas verdades, mas para descobrir as verdades interiores da

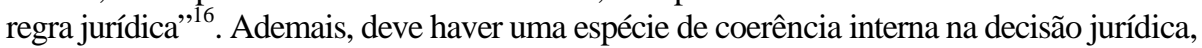
fazendo com que a interpretação do Direito entenda o sistema jurídico como um todo.

Destarte, “a decisão é resultado de cômputo, cujos fatores são os conceitos”. Essa visão se relaciona também com a postura de Pontes de Miranda com relação ao papel da linguagem como forma de comunicação que armazena o dado, conserva-o no tempo e o transmite. ${ }^{17}$

\footnotetext{
${ }^{14}$ PONTES DE MIRANDA, Francisco Cavalcante. Sistema de Ciência Positiva do Direito. Campinas: Bookseller, Tomo 4, 2005, p. 379.

${ }^{15}$ PONTES DE MIRANDA, Francisco Cavalcante. Sistema de Ciência Positiva do Direito. Campinas: Bookseller, Tomo 4, 2005, p. 385.

${ }^{16}$ PONTES DE MIRANDA, Francisco Cavalcante. Sistema de Ciência Positiva do Direito. Campinas: Bookseller, Tomo 4, 2005, p. 142.

${ }^{17}$ PONTES DE MIRANDA, Francisco Cavalcante. Sistema de Ciência Positiva do Direito. Campinas: Bookseller, Tomo 2, 2005, p. 99 e 101.
} 
O Direito costumeiro ganha importância na aplicação do Direito, mas não confere à atividade interpretativa um status de criatividade. A liberdade do juiz mesmo diante das lacunas não ultrapassa o limite da análise dos fatos sociais, onde as regras jurídicas são reveladas.

A aplicação do Direito é complexa, mas a incidência não deixa de ser infalível como referência lógica. A verdade pode estar fora do processo de decisão, mas nunca estará fora da incidência. A complexidade da verdade e da interpretação do Direito não autorizam o abandono da noção de verdade.

\section{A RELAÇÃO ENTRE A PROVA JUDICIAL E A VERDADE}

No caso do presente trabalho, define-se a prova como parte da verificação de um enunciado descritivo de fatos num processo judicial. Trata-se de uma atividade pragmática que envolve a discussão e valoração da prova judicial. A prova, nesse sentido, é o argumento linguístico que serve para corroborar a verdade ou falsidade de um enunciado descritivo num processo de decisão jurídica. Os meios de prova são disciplinados por norma jurídicas que também são objeto de interpretação de conteúdos normativos. $^{18}$

Um problema inicial a se considerar é a polissemia do termo "prova", ainda mais quando estamos lidando com a prova judicial. Um primeiro sentido em que aparece o termo é aquele que se refere aos meios pelos quais uma afirmação chega a juízo, como quando se fala em prova testemunhal ou pericial, por exemplo. Pode-se falar em meio de prova no sentido abstrato, como retratado acima, ou no sentido concreto, referindo-se a um meio de prova específico de um processo concreto, quando se refere a uma testemunha específica, por exemplo.

A diferença fundamental entre os dois significados é sentida com a análise da diferença entre os modelos tradicionais de prova legal ou valoração da prova. O primeiro modelo é aquele que aparece no início da racionalização do processo no século XII com o Direito canônico e a hierarquização da Igreja. A prova legal é uma tentativa de romper com a irracionalidade dos ordálios, duelos e mistificações que o processo apresentava até sua modernização.

Nesse modelo, atribuem-se previamente valores aos meios de prova em sentido abstrato. Dessa maneira, duas testemunhas seriam suficientes para provar um certo tipo de fato, enquanto outros só se provariam com documentos, e assim por diante. Ao final do processo, caberia ao juiz pouca liberdade na apreciação dos fatos, pois as provas estariam previamente valoradas.

No modelo da valoração livre das provas a ideia é que o juiz deve, em cada situação concreta, analisar a relevância das provas apresentadas e, portanto, deve medir as provas concretamente, analisando cada testemunha, cada documento ou perícia, não estando vinculado previamente a nenhum meio de prova.

Há, ainda, o uso da expressão prova para significar todo o resultado probatório, ou o produto resultante do processo probatório, da instrução probatória.

${ }^{18}$ VILLANOVA, Lourival. As Estruturas Lógicas e o Sistema de Direito Positivo. São Paulo: Max Limonad, 1997, p. 318. 
Nesse sentido, o resultado final da instrução probatória deve resultar num enunciado como " $p$ " está provado ou " $p$ " não está provado. ${ }^{19}$

Diante da polissemia, deve-se esclarecer que, no âmbito deste trabalho, a prova é encarada como um elemento linguístico que serve para corroborar a alegação dos fatos feita no processo. Assim, a descrição feita por uma testemunha ou a apresentação de um documento ou perícia, são descrições de elementos factuais que servirão para corroborar o valor de verdade da alegação de fato feita no processo. Sendo assim, nesse trabalho, está-se mais interessado no aspecto concreto da prova judicial, não deixando de admitir-se a discussão abstrata sobre os meios de prova.

Uma forma interessante de começar essa análise é aquela de contrapor o significado de expressões como $p$ está provado e $p$ é verdadeiro. A diferença entre o significado de tais proposições pode trazer à tona a relação entre a verdade e a prova no âmbito da Filosofia e Teoria do Direito.

A questão que nos incumbe é saber quais as consequências teóricas da separação absoluta entre prova e verdade e se resta algum contato entre os dois conceitos. A tese que afirma não haver relação alguma entre verdade e prova pode ser chamada, então, de relativista, pois defende a ideia de que o processo constitui sua própria verdade.

Mas há uma visão que se pode chamar de moderada e que defende que a afirmação $p$ está provado não significa necessariamente afirmar $p$ é verdadeiro, sem, no entanto, chegar a defender um absoluto relativismo quanto aos fatos. Essa visão se limita a reconhecer as limitações processuais à busca pela verdade e será analisada no próximo ponto.

O trabalho analisará, inicialmente, a visão que entende não haver qualquer relação entre prova e verdade. Essa visão enaltece a força constitutiva do enunciado p está provado. É a visão dos partidários da abordagem relativista da prova, segundo as quais quando o juiz diz que algo está provado ele constitui um fato que serve de premissa normativa para a conclusão apresentada na sentença. ${ }^{20}$

Sobre a relação entre verdade e prova, pode-se dizer que não existe no Direito Processual ou mesmo na Teoria do Direito quem defenda uma relação irrestrita entre verdade e prova. É difícil deixar de reconhecer que a afirmação $p$ está provado não é sinônima de $p$ é verdadeiro.

Todavia, a aceitação da confusão entre incidência e aplicação do Direito leva à defesa de uma tese relativista sobre as provas. Trata-se da tese segundo a qual uma teoria das provas substituiria a Teoria do Fato Jurídico, ou, melhor dizendo, uma teoria das provas tornaria inócua a Teoria do Fato Jurídico. Nesse sentido, a complexidade da aplicação do Direito levaria ao distanciamento entre a noção de prova judicial e a verdade.

Essa visão trata a descrição de um fato no processo como um enunciado não declaratório, exatamente da forma com que os partidários da visão formalista Kelseniana tratam a questão. É um exemplo de relativismo quanto aos fatos no Direito, pois toma a descrição factual com relação às provas como decisão normativa.

${ }^{19}$ BELTRÁN, Jordi Ferrer. Prova e verità nel diritto. Bologna: Il mulino, 2004, p. 30.

${ }^{20}$ BELTRÁN, Jordi Ferrer. Prova e verità nel diritto. Bologna: Il mulino, 2004, p. 20. 
Essa postura acredita que provar não significa demonstrar a veracidade de um fato em juízo, mas sim fixar formalmente um conjunto de fatos que servirá de pressuposto para uma decisão jurídica resultado de um processo judicial. ${ }^{21}$

Assim é que Paulo de Barros Carvalho defende a tese de que:

O discurso prescritivo do Direito posto indica, fato por fato, os instrumentos credenciados para constituí-los, de tal sorte que os acontecimentos do mundo social que não puderem ser relatados com tais ferramentas de linguagem não ingressam nos domínios do jurídico, por mais evidentes que sejam. ${ }^{22}$

É uma forma abordagem que está amparada na postura kelseniana, já analisada anteriormente, e que defende a diferença entre fato e evento. Para essa tese, como já vimos, o fato, em Direito, é somente aquele descrito pela linguagem jurídica competente, que é a linguagem processual, ou a linguagem das provas.

Conforme lição de Hans Kelsen:

A condição estatuída na norma jurídica geral não é um delito efetivamente sucedido, mas a constatação do órgão legal competente de que um delito se realizou. Esta constatação também de modo algum é um enunciado em sentido lógico. Ela não tem sentido descritivo, ie., declaratório, senão constitutivo. ${ }^{23}$

É por isso que uma proposição do tipo $p$ está provado não pode ser considerada sinônimo de $p$ é verdadeiro e, assim, não pode ter valor de verdade. Destarte, como já vimos, mesmo que seja analisada fora do processo, seu valor de verdade não importa. O que importa para o Direito é que seja admitida como fundamento de uma decisão concreta no âmbito processual.

Essa relatividade da prova normalmente se refere, portanto, àqueles que, dentro da Teoria do Processo, argumentam que o processo judicial não atinge uma verdade absoluta por causa das limitações normativas. Deste modo, não se podendo falar em verdade absoluta, não se poderia falar em verdade em qualquer sentido, já que não existe uma verdade relativa. Essa, todavia, é uma forma radical de tratar a questão e serve, justamente, ao propósito de defender um relativismo quanto aos fatos no processo, como se verá no próximo ponto. ${ }^{24}$

\section{AS LIMITAÇÕES PROCESSUAIS À VERIFICAÇÃO DOS FATOS}

Já afirmei em outra obra que a prova jurídica tem um caráter persuasivo, porque a prova está sempre relacionada às normas jurídicas, além de a aferição dos fatos está sempre inserida num jogo de linguagem específico, sendo valorada pelos interesses de quem descreve os fatos que pretende provar. ${ }^{25}$

${ }^{21}$ CARNELLUTI, Francesco. La Prova Civile. Roma: Ateneo, 1947, p. 55.

${ }^{22}$ CARVALHO, Paulo de Barros. Direito tributário: fundamentos jurídicos da incidência tributária. São Paulo: Saraiva, 1998, p. 98.

${ }^{23}$ KELSEN, Hans. Teoria Geral das Normas. Porto Alegre: Fabris, 1986, p. 310.

${ }^{24}$ TARUFFO, Michele. Verità e probabilità nella prova dei fatti. Revista de Processo. V. 32, n. 154. São Paulo: RT. Dez. 2007, p. 212.

${ }^{25}$ CATÃO, Adrualdo de Lima. Decisão Jurídica e Racionalidade. Maceió: Edufal, 2007, p. 100. 
Sendo assim, os instrumentos linguísticos que servem para corroborar as descrições que fundamentam um pleito judicial - as provas ou os meios de prova seriam eminentemente persuasivos, estando ligados muito mais a uma visão retórica do que à busca por uma verdade.

Eis especificamente o que afirmei:

Isto implica, pois, uma visão da prova, em direito processual, como instrumento retórico e não como comprovação de uma "realidade”, e leva ao entendimento de que a aplicação do direito é que vai, numa metáfora cabível para o presente trabalho, "construir" o fato, sendo destituído de sentido falar-se em "fato puro" em contraposição a "fato jurídico" ${ }^{26}$

A existência de aspas no texto justamente nas palavras-chave demonstra a hesitação que tive em defender que fatos são simplesmente construídos pela aplicação do Direito, algo que, agora, pretendo demonstrar que não precisa ser a conclusão da aplicação de uma filosofia pragmática. O problema está, justamente, na manutenção da expressão construir e no abandono da noção de verdade.

A princípio, a ideia de que a prova tem um caráter retórico não parece ser um pensamento que precisa ser rejeitado na presente tese, já que ela está baseada na filosofia Wittgensteiniana, que pode ser interpretada como uma forma de contextualismo. O problema é a transformação do contextualismo em relativismo e o esquecimento de que a própria filosofia pragmática wittgensteiniana admite que certos fatos formam a base dos jogos de linguagem e que certos jogos de linguagem não podem prescindir da ideia de verdade.

A transformação do contextualismo em relativismo é um desdobramento da afirmação segundo a qual "fatos podem ser narrados de diferentes maneiras". Ao levar adiante tal afirmação, passa-se a fundamentar a ideia de que a prova dos fatos na órbita jurídica é "um simples feixe de convergências capazes de levar a uma adesão razoável”. Destarte, da ideia de "adesão razoável”, o contextualismo passa a defender um relativismo mitigado ao falar em "construção dos fatos”. ${ }^{27}$

Essa hesitação já aparecia no mesmo trabalho citado acima. Em referências explícitas sobre como o trabalho não pretendia ser porta-voz do relativismo quanto aos fatos, já afirmava:

Para a posição que aqui vai ser apresentada, a saída é combater as posturas essencialistas não propondo assertivas como: "não há verdades”, “o mundo é um caos", ou "a moralidade não existe”. Não se quer defender qualquer "decisionismo", "relativismo" ou "irracionalismo" nos processos de decisão jurídica. ${ }^{28}$

Enfatizando ainda mais a negação do relativismo, esse trabalho defende agora que é possível manter a noção de verdade no que se refere à prova judicial e à

${ }^{26}$ CATÃO, Adrualdo de Lima. Decisão Jurídica e Racionalidade. Maceió: Edufal, 2007, p. 105.

${ }^{27}$ RABENHORST, Eduardo Ramalho. A interpretação dos fatos no Direito. Prim@facie. Ano 02, n. 02. Disponível em <www.primafacie.br> Acesso em 17.11.2003, p. 11 e 14.

${ }^{28}$ CATÃO, Adrualdo de Lima. Decisão Jurídica e Racionalidade. Maceió: Edufal, 2007, p. 106. 
aplicação do Direito. Pode-se dizer que os enunciados descritivos são verificados com base na apreciação e valoração das provas, mas sem abdicar de um sentido cognitivo do processo. Assim, certas provas apresentadas no processo são mais coerentes,

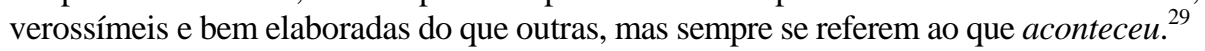

A corrente que acredita estar completamente distante a noção de prova da noção de verdade geralmente defende uma visão da prova como significando uma maneira de convencer o juiz a formular um enunciado declarativo capaz de justificar normativamente a decisão de um caso concreto.

Para Beltrán, o problema de tal visão sobre as provas é a impossibilidade de visualizar a falibilidade da afirmação $p$ está provado na aferição de um fato. Isto porque não se trata de aferir o valor de verdade de uma descrição de fatos no processo, posto que a construção do fato parte de um ato de vontade do juiz. ${ }^{30}$

Numa visão que chamo de moderada, a complexidade das regras que limitam a atividade probatória demonstra que não há relação imediata entre a prova e a verdade no processo judicial, mas isso não significa que tais noções estejam absolutamente separadas. Significa apenas que o ambiente processual possui determinadas regras que garantem a realização de outros valores além da descoberta da verdade.

Quando se pensa num processo baseado no sistema de prova legal, por exemplo, existem várias normas que impõem um contexto normativo bastante estreito com relação à descoberta da verdade. Não se trata de defender a existência de uma verdade processual (diferente da verdade real), mas de reconhecer a distância entre a verdade e o propósito do próprio processo. Em muitas situações, as suas próprias regras criam obstáculos à aferição da verdade, em favor de outros valores ou objetivos. ${ }^{31}$

Mesmo com o abandono do sistema de prova legal pelos sistemas jurídicos modernos, as limitações de tempo e dos meios capazes de trazer dados ao processo muitas vezes impossibilitam uma pesquisa cognitiva mais acurada e livre. Isto ocorre porque o próprio processo não tem por fito unicamente a busca pela verdade. Outros valores são importantes no processo, como a segurança jurídica e a manutenção da paz social. Muitas vezes, a solução rápida do conflito se faz necessária, e, nesses casos, a pesquisa dos fatos se torna supérflua diante de outros tantos interesses defendidos pelo processo judicial. ${ }^{32}$

Pontes de Miranda evidencia, no entanto, a importância das regras que regulam a enunciação de fatos por meio de provas, mostrando, mais uma vez, a abertura da sua teoria à consideração da complexidade na aferição dos fatos jurídicos. As questões do ônus da prova e dos tipos ou meios de prova cabem à dogmática jurídica processual dirimir e servem para regular a cognição sobre os fatos no processo.

\footnotetext{
${ }^{29}$ ALCHOURRÓN, Carlos E.; BULYGIN, Eugenio. Análisis lógico y derecho. Madrid: Centro de Estudios Constitucionales, 1991, 314.

${ }^{30}$ BELTRÁN, Jordi Ferrer. Prova e verità nel diritto. Bologna: Il mulino, 2004, p. 20.

${ }^{31}$ TARUFFO, Michele. Verità e probabilità nella prova dei fatti. Revista de Processo. V. 32, n. 154. São Paulo: RT. Dez. 2007, p. 213.

32 TARUFFO, Michele. Verità e probabilità nella prova dei fatti. Revista de Processo. V. 32, n. 154. São Paulo: RT. Dez. 2007, p. 213.
} 
Seguindo esse mesmo caminho, as limitações com relação à prova também são lembradas quando se esclarece a existência de regras específicas que determinam os meios de prova cabíveis no Direito:

Tanto em ciência quanto no Direito, há certos critérios que estabelecem o que há de se considerar como prova para a verdade de um enunciado empírico, mas no Direito há limitações a respeito do tipo e da quantidade dos meios de prova, admissíveis num processo judicial. Por exemplo, a existência de certos contratos só pode provar-se por meio de documentos escritos; o número de testemunhas que uma parte pode apresentar pode estar sujeito a restrições, etc. ${ }^{33}$

O papel das partes na alegação e prova da verdade também é enfatizado, principalmente no âmbito do processo civil, que lida com interesses privados na maioria das vezes. Nesses casos o ônus da prova tem papel importante e se sobrepõe à necessidade de encontrar a verdade dos fatos alegados em juízo.

Isto quer dizer que a prova não dá acesso direto à verdade e à incidência já que nenhuma prova é absoluta. Por exemplo, para Pontes de Miranda, o juiz não está adstrito a considerar verdadeiros os fatos confessados, já que ele pode aplicar o princípio da livre apreciação da prova e deixar de lado a confissão em favor de outras provas concretas. Destarte, nenhuma prova pode, por si só, servir de critério para a verdade de uma descrição fática. ${ }^{34}$

Ademais, existem as limitações decorrentes da própria diferença entre as descrições de fato que se apresentam ao processo e a distância entre a prova e o fato que se pretende provar. Os enunciados descritivos que se pretendem provar podem ser, nesse sentido, diretos ou indiretos, com relação ao enunciado final do fato jurídico.

Trata-se da distância entre os fatos brutos e os fatos jurídicos. Por fatos brutos entende-se aqueles que ainda estão destituídos de qualificação jurídica. Não se quer defender a existência de fatos fora da linguagem. Isso porque certos fatos, antes de chegar ao processo, são narrados com base em linguagem comum, não jurídica. Os fatos jurídicos surgem pela qualificação jurídica de fatos concretos. A qualificação jurídica nada mais é, destarte, do que a redescrição de fatos brutos, com base na linguagem prevista abstratamente nas normas jurídicas. ${ }^{35}$

Para provar que o sujeito cometeu homicídio, por exemplo, faz-se necessário provar fatos específicos que, isoladamente, nem sempre podem ser fatores determinantes para a comprovação do fato jurídico. Prova-se que o sujeito estava no lugar do crime; prova-se que havia resíduos de pólvora nas mãos; prova-se que o sujeito morreu por conta das lesões. Tudo isso junto, provaria o homicídio.

De outro lado, cada uma dessas comprovações específicas também pode sofrer perguntas sobre critérios. O que significa morrer por causa das lesões? Cada um dos

\footnotetext{
${ }^{33}$ ALCHOURRÓN, Carlos E.; BULYGIN, Eugenio. Análisis lógico y derecho. Madrid: Centro de Estudios Constitucionales, 1991, 311.

${ }^{34}$ PONTES DE MIRANDA, Francisco Cavalcante. Comentários ao Código de Processo Civil. Tomo IV. Rio de Janeiro: Forense, 1979, p. 327.

${ }^{35}$ LARENZ, Karl. Metodologia da Ciência do Direito. Lisboa: Fundação Calouste Gulbekian, 1991, p. 396.
} 
critérios estabelecidos como resposta será passível de ser provado concretamente, só aí resultado na afirmação de que o sujeito morreu por causa das lesões está provada. Essa decomposição pode ser feita até o limite imposto pelo próprio jogo de linguagem, e ela só faz sentido quando os critérios são controvertidos.

A prova, para construir a narrativa, precisa, portanto identificar fatos concretos que, inicialmente, não fazem a descrição final estar provada. Seguindo no exemplo, imaginemos que a descrição que se pretende provar verdadeira é a de que o sujeito não cometeu crime de homicídio. Quando, nesse caso, usa-se um álibi, ele leva ao entendimento de que o sujeito não estava no local do crime, mas isso não quer dizer, imediatamente, que o sujeito não cometeu o crime. Antes é necessário passar pela dedução da pressuposição geral de que não se pode estar em dois lugares ao mesmo tempo, além de outros fatores como a hora da morte da vítima.

Por isso é que Carnelutti fala em prova direta e indireta, distinção que é aceita na tradicional doutrina processual. A prova direta seria aquela da qual se deduz imediatamente o fato que se pretende provar, ou aquela em que o fato a ser provado se apresenta imediatamente diante do verificador por meio da prova, como um vídeo ou o exame de DNA, por exemplo. ${ }^{36}$

Mas quase nunca a prova se apresenta dessa maneira. Muitas vezes temos a prova indireta, que é aquela que, em grau maior ou menor, pode-se deduzir dela o fato a ser provado, mas essa dedução não é imediata. Seria o caso de uma prova testemunhal, por exemplo, que pode estar mais ou menos perto do fato a ser provado. Imagine-se alguém que viu o acusado comprando uma arma antes da ocorrência do crime. Aqui temos uma prova indireta com relação ao fato do homicídio. Está numa distância específica do fato a ser provado. ${ }^{37}$

Há ainda a limitação temporal. A prova deve ser produzida dentro de um período de tempo e a controvérsia tem que ser resolvida dentro dos limites temporais fixados pelas normas jurídicas. Isto se refere claramente à proteção da estabilidade das relações e a necessidade de dirimir conflitos.

Outro ponto importante para considerar é que a controvérsia sobre a verdade tem que ser resolvida por um ato de autoridade que põe um ponto final da verificação da verdade do enunciado, limitando a apreciação da verdade. Trata-se de uma limitação típica do Direito, que precisa terminar o conflito e não perpetuá-lo.

É certo que tais limitações existem porque o Direito não está interessado primordialmente em descobrir verdades, mas em solucionar conflitos. Entretanto, deve-se destacar que os conflitos sociais são resolvidos com normas gerais, e a aplicação de tais normas a casos particulares requer frequentemente a determinação da verdade de enunciados descritivos. ${ }^{38}$

A separação entre prova e verdade não é, por conseguinte, absoluta. Pelo contrário. Reconhecer o caráter descritivo do enunciado $p$ está provado demonstra justamente

${ }^{36}$ CARNELUTTI, Francisco. Sistema de Derecho Procesal Civil. V. II. Buenos Aires: Uteha, 1944, p. 402.

${ }^{37}$ CARNELUTTI, Francisco. Sistema de Derecho Procesal Civil. V. II. Buenos Aires: Uteha, 1944, p. 402.

${ }^{38}$ ALCHOURRÓN, Carlos E.; BULYGIN, Eugenio. Análisis Lógico y Derecho. Madrid: Centro de Estudios Constitucionales, 1991, 312 
que a complexidade do processo de aferição da verdade no processo não pode levar ao abandono da própria noção de verdade, como veremos no próximo ponto.

\section{A PROVA JUDICIAL E O DEVER DE VERDADE}

Percebe-se que a análise da doutrina pontesiana vai influenciar claramente sua visão sobre as provas no processo judicial. Essa visão, no âmbito do presente trabalho, pode servir para apoiar o entendimento segundo o qual o ambiente processual é um jogo de linguagem que exige a atribuição de valor de verdade às proposições descritivas e, assim, a prova judicial não está tão distante da noção de verdade.

Não se quer, com isso, é sempre importante enfatizar, deixar de lado o aspecto pragmático do Direito. Como escreveu Torquato Castro, o Direito tem por fim a ação e não o conhecimento. Exagera, no entanto, pois faz a injusta separação entre conhecer e agir, algo que a visão pragmática não precisa aceitar. Destarte, quando se defende o aspecto cognitivo do processo de decisão jurídica, não se quer deixar de lado a importância valorativa desse conhecer. ${ }^{39}$

Trata-se, destarte, de um valor jurídico atribuído à noção de verdade. Esse valor processual resulta evidente quando se pensa que o processo não visa a simplesmente resolver a controvérsia, mas, além disso, visa a aplicar uma decisão considerada justa. Como se posiciona Michele Taruffo: "Da questo punto di vista, la verità della decisione sui fatti costituisce uma condizione necessária della giustizia della decisione stessa". 40

Isso significa que a decisão judicial deve estar baseada em critérios razoáveis aos seus propósitos, não fazendo sentido pensar num processo de decisão jurídica que vise a uma decisão qualquer, independentemente dos fatos. Trata-se de um postulado do Direito moderno que o processo seja um ambiente de cognição, e que baseie suas decisões na verdade dos fatos, deixando-se de lado os duelos e as provas irracionais, típicos da Idade Média.

Seguindo essa linha de raciocínio, afirma Adriano Soares:

Se afirmo que todo ato de aplicação é constitutivo do fato jurídico, como faz a teoria do realismo lingüístico, não haveria espaço para as sentenças declaratórias, por exemplo, que dizem respeito ao ser ou não-ser das relações jurídicas, anteriormente à sentença que as declarou. ${ }^{41}$

Pontes de Miranda, ao analisar o processo judicial, trata-o como ambiente cognitivo, e se refere à prova como referência a fatos, a elementos do suporte fático, e aos fatos jurídicos, coerentemente com a sua posição filosófica. Ele menciona tanto

\footnotetext{
${ }^{39}$ CASTRO, Torquato. Teoria da situação jurídica em direito privado. Anuário do Mestrado em Direito do Recife. N. 1. Jan./Dez. 1976, p. 31 e 33.

40 "Deste ponto de vista, a verdade da decisão sobre os fatos condição necessária da justiça dessa decisão". TARUFFO, Michele. Verità e probabilità nella prova dei fatti. Revista de Processo. V. 32, n. 154. São Paulo: RT. Dez. 2007, p. 215.

${ }^{41}$ COSTA, Adriano Soares. Teoria da incidência da norma jurídica: crítica ao realismo lingüístico de Paulo de Barros Carvalho. São Paulo: Malheiros. 2009, p. 59.
} 
os fatos que entram na composição de suporte fáticos quanto à verdade da existência da própria norma jurídica que incide sobre o suporte fático. ${ }^{42}$

Ele destaca, ainda, que a prova não é uma exclusividade do Direito Processual, sendo também parte da regulamentação do Direito Material, já que a prova não se dá somente em juízo, mas em toda situação em que se faz necessário o convencimento da verdade da incidência da norma jurídica. Assim, mesmo a aplicação do direito não é exclusividade dos órgãos competentes.

Dessa forma, quando a prova ocorre no âmbito processual, a necessidade é do convencimento do juiz, mas nem sempre ele é o único destinatário da prova. A prova serve também à autoridade administrativa e, no âmbito do Direito privado, aos contratantes. Quando o juiz, ou a autoridade a que a prova se refere se convence, ou seja, considera o fato provado, isso quer dizer que ele enunciou a mesma sentença descritiva que o interessado enunciara no processo. Os fatos enunciados no processo são os fatos relevantes para a causa. ${ }^{43}$

A aplicação do Direito para Pontes de Miranda é o campo da tutela jurídica, por meio da qual se apresenta a res in judicio deducta. Essa nada mais é do que a alegação de que um fato ocorreu, uma regra incidiu e efeitos jurídicos foram gerados e não realizados espontaneamente.

Muitas vezes, a aplicação do Direito não se dá corretamente, seja porque não havia provas suficientes, seja porque o juiz errou. Mas, independentemente do erro, a incidência é o fato que se pretende provar no processo, fato esse que independe do resultado final do processo de decisão, podendo ou não coincidir com ele.

Por isto Pontes de Miranda afirma que o processo judicial "serve à aplicação da lei que incidiu, sem que o obrigado cumprisse a sua obrigação, ou para aquela realização de Direito objetivo sem sujeito particular da obrigação, o que se verifica em muitos casos de sentença constitutiva". ${ }^{44}$

A litigiosidade, para Pontes de Miranda, leva à necessidade de se afastar a dúvida. É por isso que cabe ao juiz entregar a prestação jurisdicional com o máximo de exatidão e certeza, nos limites contextuais a que está exposto. Essa necessidade está na base da própria noção de processo de conhecimento.

O processo é, portanto, ambiente cognoscitivo, que serve para enunciar fatos jurídicos com vistas à prestação estatal que as partes requereram. O conjunto de alegações fáticas é corroborado pelos documentos, interrogatórios, depoimentos, periciais, que formam o conjunto probatório e isso envolve, obviamente, a valoração e análise da coerência dos argumentos.

Isso não quer dizer, como já mencionado, que o objetivo final de todo procedimento probatório não seja a convicção do juiz sobre a verdade. Quando isso não é possível,

${ }^{42}$ PONTES DE MIRANDA, Francisco Cavalcante. Comentários ao Código de Processo Civil. Tomo IV. Rio de Janeiro: Forense, 1979, p. 311.

${ }^{43}$ PONTES DE MIRANDA, Francisco Cavalcante. Comentários ao Código de Processo Civil. Tomo IV. Rio de Janeiro: Forense, 1979, p. 313.

${ }^{44}$ PONTES DE MIRANDA, Francisco Cavalcante. Sistema de Ciência Positiva do Direito. Campinas: Bookseller. Tomo 2, 2005, p. 305. 
ou viável, a técnica jurídica encontra instrumentos para manter a ordem e a paz na solução de conflitos, deixando a busca pela verdade de lado em favor de outros valores.

Essas situações específicas não podem significar um abandono da verdade pelo processo ou um distanciamento da prova com relação aos fatos que pretende provar. Daí porque, em Pontes de Miranda, o dever de verdade, antes de tudo, é um dever de justiça, e o juiz tem de buscar a verdade no processo de decisão. A decisão tem que ser justa, e a justeza da decisão sobre os fatos está relacionada, em Pontes de Miranda, à exatidão da busca pelos fatos. Assim ele se pronuncia:

Se, como aqui temos que exigir, ficamos no campo do Direito, logo percebemos que há o dever de verdade, que supõe esteja na mente do legislador, para que a lei faça o bem social, o dever de verdade de quem interpreta as leis e o dever de verdade de quem as tem que aplicar. ${ }^{45}$

O dever de verdade está, portanto, na base do próprio conceito de prova processual. Nesse sentido, Carnelutti afirma que "Probar indica una actividad del espíritu dirigida a la verificación de un juicio. Lo que se prueba es una afirmación, cuando se habla de probar un hecho, ocurre así por el acostumbrado cambio entre la afirmación y el hecho afirmado". ${ }^{6}$

O objeto da prova não pode ser outra coisa que não o fato a ser provado. Seguindo essa linha de argumentação, continua Carnelutti: "Hablamos de probas verdaderas y falsas, queriendo indicar con ello las pruebas que son idóneas para fundar un juicio verdadero o falso". ${ }^{47}$

Isso fica ainda mais evidente quando se demonstra a existência, em qualquer Direito processual moderno, das precauções processuais contras as provas falsas. Punições contra a má-fé processual e a obrigação jurídica de dizer a verdade. Trata-se do dever de não lesar por adulteração dos fatos. Por isto mesmo a má-fé na produção de provas deve ser punível pela dogmática processual. Para Pontes de Miranda, as regras contra "atitudes maldosas, ou de fundamento falso, tinham de surgir no plano de Direito processual”. 48

No nosso Código de Processo Civil, vários sãos os dispositivos que tratam do assunto. No artigo 14, lemos que é dever da parte e de todos aqueles que participam do processo "expor os fatos em juízo conforme a verdade”. Ainda o artigo 339, estabelecendo que "ninguém se exime do dever de colaborar com o Poder Judiciário para o descobrimento da verdade”. Sobre a má-fé, temos a expressa menção do artigo 17, II, em que "reputa-se litigante de má-fé aquele que altera a verdade dos fatos”.

Evidentemente, a defesa da tese de que a verdade está relacionada com a prova não implica negar a diferença existente entre o enunciado $p$ está provado e p é verdadeiro.

${ }^{45}$ PONTES DE MIRANDA, Francisco Cavalcante. Comentários ao Código de Processo Civil. Tomo IV. Rio de Janeiro: Forense, 1979, p. 324 e 382.

${ }^{46}$ CARNELUTTI, Francisco. Sistema de Derecho Procesal Civil. V. II. Buenos Aires: Uteha, 1944, p. 398.

${ }^{47}$ CARNELUTTI, Francisco. Sistema de Derecho Procesal Civil. V. II. Buenos Aires: Uteha, 1944, p. 458.

${ }^{48}$ PONTES DE MIRANDA, Francisco Cavalcante. Comentários ao Código de Processo Civil. Tomo IV. Rio de Janeiro: Forense, 1979, p. 324. 
Apesar disso, essa diferença não significa uma absoluta distância, como quer fazer crer a postura que nega o caráter de descrição quando o enunciado sobre fatos é feito no processo judicial.

A questão é que reconhecer a força declarativa do enunciado $p$ está provado não necessariamente significa defender uma teoria da verdade como correspondência com a realidade. Isso fica claro quando se percebe a separação entre o que seria uma verdade processual e uma verdade real, uma distinção controversa no âmbito do Direito Processual, e que pode justificar a defesa do relativismo quanto aos fatos.

Essa distinção, todavia, poderia significar simplesmente que o que é decidido no processo por meio das provas não necessariamente corresponde ao que se pode chamar de verdadeiro. Dessa maneira, mais plausível do que a distinção entre verdade processual e verdade real é a atenção para a diferença de significado entre as expressões $p$ está provado e $p$ é verdadeiro.

Igualmente, é possível dizer que p está provado, mas não é verdadeiro, sobretudo quando essa afirmação é feita do ponto de vista externo ao processo de decisão jurídica considerado formalmente. Muitas vezes o fato que está provado hoje pode, amanhã, vir a encontrar novas provas que corroboram a afirmação de sua falsidade, o que pode legitimar, no Direito brasileiro, a revisão criminal ou fundamentar ações rescisórias.

O que não se pode é renunciar à falibilidade da decisão judicial e à necessidade de o processo buscar a verdade dos fatos nos limites das suas possibilidades, renunciando à mera possibilidade lógica de se argumentar uma correspondência com a realidade sem fundamento metafísico.

Abandona-se, dessa forma, a distinção tradicional entre verdade material e verdade formal, ou entre verdade real e verdade processual. O processo não requer apenas uma verdade formal em detrimento da verdade real que se atingiria fora dele. Em primeiro lugar porque o ambiente processual, como visto, requer a busca pela verdade como realização de seus propósitos mais básicos. Além do mais, fora do ambiente processual também há limitações à aferição da verdade, não fazendo sentido pensar na verdade apenas fora do ambiente processual.

Qualquer proposição descritiva é considerada com relação aos seus métodos e critérios de aferição, presentes nos diversos jogos de linguagem, mas não precisamos falar em em verdades diferentes de acordo com cada jogo de linguagem. Por isso, não há coerência em falar de uma verdade processual em detrimento de uma verdade real.

A distinção importante não se dá entre a verdade de dentro do processo e a verdade de fora dele. O mais importante, para o processualista e para a discussão sobre a relação entre verdade e prova é a distinção entre os diversos tipos de processo e suas diferentes preocupações em termos de aferição da verdade dos fatos jurídicos. Existem determinados processos em que a busca pela verdade é mais importante do que em outros. $^{49}$

${ }^{49}$ TARUFFO, Michele. Verità e probabilità nella prova dei fatti. Revista de Processo. V. 32, n. 154. São Paulo: RT. Dez. 2007, p. 213. 
Por isso, mesmo a decisão final de um caso concreto num processo judicial não põe fim à questão sobre se a incidência ocorreu ou não. Tal autoridade não põe um ponto final na questão da verdade, apesar de torná-la irrelevante para efeitos jurídicos. Dizer isto é dizer muito menos que a linguagem competente do Direito constrói a verdade processual, independentemente da verdade real.

\section{REFERÊNCIAS BIBLIOGRÁFICAS}

ALCHOURRÓN, Carlos E.; BULYGIN, Eugenio. Análisis lógico y derecho. Madrid: Centro de Estudios Constitucionales, 1991.

BELTRÁN, Jordi Ferrer. Prova e verità nel diritto. Bologna: Il Mulino, 2004.

CARNELLUTI, Francesco. La Prova Civile. Roma: Ateneo, 1947.

CARNELUTTI, Francisco. Sistema de Derecho Procesal Civil. V. II. Buenos Aires: Uteha, 1944.

CARVALHO, Paulo de Barros. Direito tributário: fundamentos jurídicos da incidência tributária. São Paulo: Saraiva, 1998.

CASTRO, Torquato. Teoria da situação jurídica em direito privado. Anuário do Mestrado em Direito do Recife. N. 1. Jan./Dez. 1976.

CATÃO, Adrualdo de Lima. Decisão Jurídica e Racionalidade. Maceió: Edufal, 2007.

COSTA, Adriano Soares. Teoria da incidência da norma jurídica: crítica ao realismo lingüístico de Paulo de Barros Carvalho. São Paulo: Malheiros. 2009, p. 45.

GUSMÃO, Paulo Dourado de. As idéias do jovem Pontes de Miranda. Conferências do III Congresso Brasileiro de Filosofia do Direito: em homenagem a Pontes de Miranda. João Pessoa: Edições Grafset, Jun. 1988.

KELSEN, Hans. Teoria Geral das Normas. Porto Alegre: Fabris, 1986.

LARENZ, Karl. Metodologia da Ciência do Direito. Lisboa: Fundação Calouste Gulbekian, 1991, p. 396.

PONTES DE MIRANDA, Francisco Cavalcante. Comentários ao Código de Processo Civil. Tomo IV. Rio de Janeiro: Forense, 1979.

PONTES DE MIRANDA, Francisco Cavalcante. Sistema de Ciência Positiva do Direito. Campinas: Bookseller. Tomo 2, 2005.

PONTES DE MIRANDA, Francisco Cavalcante. Sistema de Ciência Positiva do Direito. Campinas: Bookseller. Tomo 3, 2005.

PONTES DE MIRANDA, Francisco Cavalcante. Tratado de Direito Privado. Campinas: Bookseller. Tomo 1, 1999.

RABENHORST, Eduardo Ramalho. A interpretação dos fatos no Direito. Prim@facie. Ano 02. N. 02. Disponível em <www.primafacie.br> Acesso em 17 nov. 2003, p. 11 e 14.

TARUFFO, Michele. Verità e probabilità nella prova dei fatti. Revista de Processo. V. 32. n. 154. São Paulo: RT. Dez. 2007.

VILLANOVA, Lourival. As Estruturas Lógicas e o Sistema de Direito Positivo. São Paulo: Max Limonad, 1997. 